\title{
Can dialysis modality influence cardiovascular outcome?
}

\author{
Rukshana Shroff
}

Received: 23 March 2012 /Revised: 5 May 2012 / Accepted: 7 May 2012 / Published online: 3 June 2012

(C) IPNA 2012

\section{Introduction}

Children with chronic kidney disease (CKD), particularly those on long-term dialysis, have a significant burden of cardiovascular disease (CVD). The mortality of children on dialysis is 700 -fold higher than that of their healthy peers [1], and CVD is the most common cause of death [2-4]. Amongst children with CKD, both cardiac [5] and vascular damage and calcification [6] are present from the pre-dialysis CKD stages, and these increase in prevalence and severity on dialysis [6]. Importantly, all paediatric and adult studies conducted to date have shown that CVD progression with deteriorating cardiac function and progressive vascular calcification is associated with a long dialysis vintage $[1,3,6-11]$ on both haemodialysis (HD) and peritoneal dialysis (PD).

\section{Cardiovascular mortality among patients on PD and HD}

Adult studies have reported variable cardiovascular outcomes among patients on PD and HD. In a recent study among adult dialysis recipients, mortality was lower in incident PD patients than in a matched HD group, and PD was associated with improved long-term survival amongst patients aged $<65$ years and those without CVD and diabetes [12]. In the only randomised controlled study conducted to date that compares dialysis modalities, incident PD patients had a significantly improved survival (hazard ratio 3.6, $95 \%$ confidence intervals 0.8-15.4) compared to incident HD patients [13]. However,

\section{R. Shroff $(\bowtie)$}

Renal Unit, Great Ormond Street Hospital for Children,

Great Ormond Street,

London WC1N 3JH, UK

e-mail: Rukshana.Shroff@gosh.nhs.uk there was no difference in the risk of developing de novo CVD in incident PD and HD patients, although patients with preexisting coronary artery disease or congestive heart failure had significantly worse survival on PD than on HD [14]. The prevalence of cardiac valvular calcification ranges from 32 to $47 \%$ in PD patients compared to $19-84 \%$ in HD patients based on the results of several cohort studies in adult dialysis patients; one reason for the wide variation in the differences reported may be differences in the management of mineral dysregulation per se and not in the choice of dialysis modality.

Data from the Australia and New Zealand Dialysis and Transplant Registry have shown that amongst children on chronic dialysis the number of deaths is approximately twofold higher among those on HD compared to PD [1]. However, these data are not adjusted for time on dialysis, and the management of CKD in many HD patients may in fact have failed on PD, putting these patients at increased mortality risk. More recent reports from the United States Renal Data System (USRDS) describe similar mortality rates; 28 and $32 \%$ of all deaths that occur among patients on PD and HD, respectively, are due to a cardiovascular cause [2]. As with all registry reports these data are retrospective, the selection of dialysis modality may have influenced outcome and, in reality, children often switch between dialysis modalities and return to dialysis after a failed transplant. A randomised controlled trial in the field is highly unlikely, and data on cardiovascular outcomes in matched cohorts of children on PD and HD are scarce. Moreover, it is difficult to extrapolate outcomes from adult studies. Children starting dialysis rarely have vascular calcification or overt CVD [6,9]. In fact, children are more likely to develop arteriosclerosis with calcification of the tunica media and concentric thickening of the vessel wall, whereas adults with CKD have a combination of intimal and medial calcification, probably compounded by coexisting diabetes, dyslipidaemia and hypertension. 
In a recent article published in Pediatric Nephology, Chavarria et al. show for the first time that children on HD have a worse cardiovascular outcome that those on PDindependent of the time on dialysis [15]. Although this is a single-centre cohort study with an unmatched population and a very small number of patients, interesting associations are shown between dialysis modality and carotid artery intimamedia thickness (cIMT). In overall and subgroup analyses, HD patients are shown to have a significantly higher cIMT than their PD counterparts. Moreover, based on a comparison of children who had exclusively received PD $(n=29)$ or HD $(n=6), \mathrm{HD}$ was found to be associated with a 15 -fold higher risk (95\% confidence interval 1.3-164) of an increased cIMT that was independent of the time on dialysis. The cIMT is a well-validated surrogate marker of cardiovascular damage and predicts future cardiovascular events. An increased cIMT is also associated with greater left ventricular mass index and is direct evidence of vessel calcification.

\section{Risk factors for CVD development in dialysis patients}

Mineral dysregulation and its management, intradialytic haemodynamic changes and inflammation are key factors that may influence CVD development in children on dialysis. PD and HD involve overlapping but somewhat different pathophysiological processes that contribute to the unacceptably high cardiovascular burden of dialysis.

\section{Mineral dysregulation}

The International Pediatric Peritoneal Dialysis Network (IPPN), which includes data on nearly 900 children and adolescents from 24 countries, has reported that the prevalence of hyperphosphatemia increases with age $(6 \%$ in young infants, $81 \%$ in adolescents) and loss of residual renal function [16]. Mineral dysregulation with high calcium $(\mathrm{Ca})$, phosphorus $(\mathrm{P})$ and parathyroid hormone $(\mathrm{PTH})$ levels as well as medication dosages of Ca-based $\mathrm{P}$ binders and vitamin $\mathrm{D}$ compounds have been associated with abnormal vascular measures $[3,8,9,11,17]$ and are considered to be direct evidence of calcification in the vessels [6]. Calcification of the coronary arteries has been reported in $15-30 \%$ of dialysis patients $[3,8,11,17]$ and observed to start as early as the first decade of life. In its early stages, calcification is predominantly in the tunica media of vessels, but it may progress to varying combinations of intimal and medial calcification. Medial calcification leads to increased vascular stiffness, systolic hypertension and left ventricular hypertrophy, whereas intimal calcification is associated with ischaemic heart disease.

Using intact arteries from children, we have shown that calcification in the vessel wall strongly correlates with a patient's mean time-averaged serum $\mathrm{Ca} \times \mathrm{P}$ [6]. When these vessel rings were cultured in graded concentrations of $\mathrm{Ca}$ and $\mathrm{P}$, dialysis vessels showed accelerated calcification in media with high levels of $\mathrm{Ca}$ and $\mathrm{P}$ [18]. Importantly, in the presence of a high level of $\mathrm{P}$, even a small increase in $\mathrm{Ca}$ in the culture medium significantly increases calcification [18]. These transient increases in $\mathrm{Ca}$ that inevitably occur in clinical practice may go unrecorded, but they can impact on ectopic calcification, particularly in the setting of high $\mathrm{P}$ conditions. HD patients are more prone to transient increases in serum $\mathrm{Ca}$ levels, such as those seen after an HD session or with the use of Ca-containing phosphate binders and vitamin $\mathrm{D}$ analogues, and this may, in part, account for the higher prevalence of calcification in some adult HD cohorts [19]. Indeed, Ca balance studies during HD have shown that the majority of HD patients are continually experiencing $\mathrm{Ca}$ overload [20]. Calcification progresses rapidly even in young patients who have baseline calcification: in one study, the coronary artery calcium (CAC) score almost doubled after a mean interval of 20 months in patients who showed evidence of initial calcification [8].

Current paediatric studies are too small and confounded to provide data on differences in mineral dysregulation and calcification between PD and HD. In their study, Chavarria et al. show an association between higher $\mathrm{Ca}$ levels (but not $\mathrm{Ca}$ intake) and increased cIMT [15]. The Ca intake from binders was higher than the normal ranges recommended by the National Kidney Foundation Disease Outcomes Quality Initiative (K/DOQI), but neither Ca intake nor P levels were implicated in the raised cIMT. The fact that the majority of their patients had high PTH levels despite hypercalcaemia suggests tertiary hyperparathyroidism with long-standing dysregulation of the Ca-P-PTH axis. High PTH levels per se have been associated with raised cIMT, vascular calcification and even myocardial fibrosis $[3,10]$.

It is hoped that the two large prospective longitudinal follow-up studies that are currently ongoing, namely, the Cardiovascular Comorbidity in Children with Chronic Kidney Disease Study (4C) and the prospective Chronic Kidney Disease in Children (CKiD) cohort study, will provide important outcome data to inform future practice.

\section{Haemodynamic effects}

Left ventricular hypertrophy (LVH) and dysfunction are the most common cardiac abnormalities seen in children with $\mathrm{CKD}$, and it has been reported that $69-82 \%$ of children starting maintenance dialysis show evidence of LVH that persists (40-85\%) during long-term dialysis [10]. LVH is most likely due to long-standing volume overload in dialysis patients, but chronic anaemia and hyperparathyroidism may also be contributory factors. Both concentric and eccentric 
patterns of LVH are seen. The IPPN registry reports a $48 \%$ prevalence of $\mathrm{LVH}$, with $29 \%$ of patients developing LVH while on $\mathrm{PD}$, and $40 \%$ undergoing regression from LVH to normal cardiac geometry [16]. Data on LVH in patients on $\mathrm{HD}$ are not separately available, but the prevalence is likely to be higher. LV dysfunction is also prevalent amongst dialysis patients, although this is often clinically silent. A report from the USRDS has shown that $31 \%$ of children with end-stage renal disease have cardiovascular events, with arrhythmias, valvular heart disease and cardiomyopathy occurring in 19.6, 11.7 and $9.6 \%$ of these children, respectively.

HD patients are particularly susceptible to myocardial ischaemia that can result from changes in the myocardial small vessels, coronary atheroma, defective vasoregulation and reduced peripheral arterial compliance [21]. HD patients may also experience relative intradialytic hypotension and haemodynamic instability related to large ultrafiltration volumes or rapid ultrafiltration that leads to changes in global and segmental myocardial blood flow and the development of myocardial ischaemia or 'stunning' [20]. Repeated onslaughts of intradialytic hypotension with ischaemiareperfusion changes lead to myocardial fibrosis, reduced systolic cardiac function and arrhythmias [21]. In one study, myocardial stunning was reported in 11/12 children receiving conventional HD [22].

The haemodynamic changes in PD patients are of a different nature and associated with inadequate ultrafiltration and fluid overload. These changes are related to dialysate type, glucose exposure, biocompatibility and PD modality; the IPPN registry reports that children on continuous ambulatory peritoneal dialysis have a greater risk of LVH, whereas salt-losing patients with renal hypodysplasia are protected from fluid overload and LVH [16]. Overhydration leads to elevated serum concentrations of natriuretic peptides owing to their increased production by the myocardium; high plasma concentrations of $N$-terminal propeptide B-type natriuretic peptide has been shown in the 'stressed hearts' of paediatric CKD patients [23] and has been associated with an eightfold increase in the risk of mortality in adult PD patients [24].

\section{Inflammation}

As in the general population, C-reactive protein (CRP) predicts all-cause and cardiovascular mortality in patients on HD and PD, although CRP levels tend to be lower in those on PD. In paediatric dialysis patients, a single random high-sensitivity CRP value has been associated with the degree of coronary calcification in some studies [3, 11], while others have shown that despite elevated interleukin (IL)-6 and IL-8 levels in all children on HD, these were not different in patients with calcification [25].
The accumulation of advanced glycation end-products (AGEs), oxidative stress and local inflammatory stimuli contribute towards vascular damage. Concentrations of plasma AGEs are elevated in patients on PD and HD compared with levels in healthy individuals, but these concentrations do not differ between the two dialysis techniques. Adult patients on PD have been found to have less vessel stiffness after 1 year of therapy than those on HD. 'Biocompatible' dialysis solutions have resulted in a reduction of the amounts of glucose degradation products, and their use is associated with a decrease in the levels of plasma AGEs. While these solutions are likely to better preserve the peritoneal membrane and thus allow for better dialysis, their clinical relevance to cardiovascular or all-cause mortality is unknown.

The inflammatory state may be associated with malnutrition, and the combination is directly linked with a high risk of atherosclerosis known as the malnutrition-inflammationatherosclerosis (MIA) complex [16]. Interestingly, although inflammation has been shown to promote the development of intimal calcification with macrophage infiltration of lipidrich plaques, it was not linked with coronary calcification in a small cohort of children on haemodialysis [25] nor seen at the cellular level in vessels from children on dialysis [6].

\section{Conclusions: the need for intensified dialysis regimens}

The conventional three-times-per-week regimen of HD and PD offers only sub-optimal clearance of fluid and uraemic toxins. Intensifying $\mathrm{HD}$ treatment to achieve a single pool Kt/ $\mathrm{V}>1.71$ does not translate to an improved survival. Newer modalities of dialysis in the form of adding in convective clearance with haemodiafiltration (HDF) or increasing dialysis time with quotidian haemodialysis (QHD) significantly reduce cardiovascular morbidity and improve survival in adults, although this has not been proven in a randomized controlled trial [26]. At the present time, HDF and QHD are only practiced in a handful of paediatric centres worldwide. Anecdotal reports children on daily HDF showing improved growth [27] and better phosphate clearance, normalisation of PTH and nutrition in children on QHD [28] suggest that intensified dialysis may indeed improve cardiovascular outcomes, with reported survival rates of patients on QHD comparable to those of deceased donor transplantation [29]. In HDF, both the convective and diffusive clearance of uraemic toxins across a wide molecular weight range, better tolerance of and greater fluid removal, biocompatibility of high-flux dialysis membranes and 'ultrapure' dialysis water together improve survival by $35 \%$ in adults on HDF [30]. Multicentre trials or at least large paediatric registries should be established to study the effects, including long-term cardiovascular outcomes, of HDF and QHD in children. 
PD and HD carry a very high burden of cardiovascular morbidity and mortality risk, much of which is due to the dysregulation of modifiable risk factors. Vascular calcification is known to progress rapidly on dialysis, so attempts must be directed at prevention rather than 'damage limitation'. Where transplantation is not feasible, intensified dialysis regimens may be the preferred option for children.

\section{References}

1. McDonald SP, Craig JC (2004) Long-term survival of children with end-stage renal disease. N Engl J Med 350:2654-2662

2. US Renal Data System (2011) USRDS 2011 Annual data report: atlas of chronic kidney disease and end-stage renal disease in the United States. National Institutes of Health, National Institute of Diabetes and Digestive and Kidney Diseases, Bethesda

3. Oh J, Wunsch R, Turzer M, Bahner M, Raggi P, Querfeld U, Mehls O, Schaefer F (2002) Advanced coronary and carotid arteriopathy in young adults with childhood-onset chronic renal failure. Circulation 106:100-105

4. Groothoff JW, Gruppen MP, Offringa M, Hutten J, Lilien MR, Van De Kar NJ, Wolff ED, Davin JC, Heymans HS (2002) Mortality and causes of death of end-stage renal disease in children: a Dutch cohort study. Kidney Int 61:621-629

5. Mitsnefes MM, Kimball TR, Witt SA, Glascock BJ, Khoury PR, Daniels SR (2003) Left ventricular mass and systolic performance in pediatric patients with chronic renal failure. Circulation 107:864-868

6. Shroff RC, McNair R, Figg N, Skepper JN, Schurgers L, Gupta A, Hiorns M, Donald AE, Deanfield J, Rees L, Shanahan CM (2008) Dialysis accelerates medial vascular calcification in part by triggering smooth muscle cell apoptosis. Circulation 118:1748-1757

7. Civilibal M, Caliskan S, Kurugoglu S, Candan C, Canpolat N, Sever L, Kasapcopur O, Arisoy N (2009) Progression of coronary calcification in pediatric chronic kidney disease stage 5. Pediatr Nephrol 24:555-563

8. Goodman WG, Goldin J, Kuizon BD, Yoon C, Gales B, Sider D, Wang Y, Chung J, Emerick A, Greaser L, Elashoff RM, Salusky IB (2000) Coronary-artery calcification in young adults with endstage renal disease who are undergoing dialysis. N Engl J Med 342:1478-1483

9. Litwin M, Wuhl E, Jourdan C, Niemirska A, Schenk JP, Jobs K, Grenda R, Wawer ZT, Rajszys P, Mehls O, Schaefer F (2008) Evolution of large-vessel arteriopathy in paediatric patients with chronic kidney disease. Nephrol Dial Transplant 23:2552-2557

10. Mitsnefes MM, Daniels SR, Schwartz SM, Khoury P, Strife CF (2001) Changes in left ventricular mass in children and adolescents during chronic dialysis. Pediatr Nephrol 16:318-323

11. Shroff RC, Donald AE, Hiorns MP, Watson A, Feather S, Milford D, Ellins EA, Storry C, Ridout D, Deanfield J, Rees L (2007) Mineral metabolism and vascular damage in children on dialysis. J Am Soc Nephrol 18:2996-3003

12. Weinhandl ED, Foley RN, Gilbertson DT, Arneson TJ, Snyder JJ, Collins AJ (2010) Propensity-matched mortality comparison of incident hemodialysis and peritoneal dialysis patients. J Am Soc Nephrol 21:499-506

13. Korevaar JC, Feith GW, Dekker FW, van Manen JG, Boeschoten EW, Bossuyt PM, Krediet RT (2003) Effect of starting with hemodialysis compared with peritoneal dialysis in patients new on dialysis treatment: a randomized controlled trial. Kidney Int 64:2222-2228
14. Vonesh EF, Moran J (1999) Mortality in end-stage renal disease: a reassessment of differences between patients treated with hemodialysis and peritoneal dialysis. J Am Soc Nephrol 10:354-365

15. Chavarria LA, Aguilar-Kitsu A, Rosas P, Fajardo A, MendozaGuevara L, Sanchez L, Zepeda C, Ibarra P, Luna A, Lindholm B, Garcia-Lopez E (2012) Intima media thickness in children undergoing dialysis. Pediatr Nephrol. doi:10.1007/s00467-012-2173-1

16. Bakkaloglu SA, Borzych D, Soo Ha I, Serdaroglu E, Buscher R, Salas P, Patel H, Drozdz D, Vondrak K, Watanabe A, Villagra J, Yavascan O, Valenzuela M, Gipson D, Ng KH, Warady BA, Schaefer F (2011) Cardiac geometry in children receiving chronic peritoneal dialysis: findings from the International Pediatric Peritoneal Dialysis Network (IPPN) registry. Clin J Am Soc Nephrol 6:1926-1933

17. Civilibal M, Caliskan S, Adaletli I, Oflaz H, Sever L, Candan C, Canpolat N, Kasapcopur O, Kuruoglu S, Arisoy N (2006) Coronary artery calcifications in children with end-stage renal disease. Pediatr Nephrol 21:1426-1433

18. Shroff RC, McNair R, Skepper JN, Figg N, Schurgers LJ, Deanfield J, Rees L, Shanahan CM (2010) Chronic mineral dysregulation promotes vascular smooth muscle cell adaptation and extracellular matrix calcification. J Am Soc Nephrol 21:103-112

19. Tentori F, Blayney MJ, Albert JM, Gillespie BW, Kerr PG, Bommer J, Young EW, Akizawa T, Akiba T, Pisoni RL, Robinson BM, Port FK (2008) Mortality risk for dialysis patients with different levels of serum calcium, phosphorus, and PTH: the Dialysis Outcomes and Practice Patterns Study (DOPPS). Am J Kidney Dis 52:519-530

20. Sigrist M, McIntyre CW (2006) Calcium exposure and removal in chronic hemodialysis patients. J Ren Nutr 16:41-46

21. McIntyre CW (2009) Effects of hemodialysis on cardiac function. Kidney Int 76:371-375

22. Hothi DK, Rees L, Marek J, Burton J, McIntyre CW (2009) Pediatric myocardial stunning underscores the cardiac toxicity of conventional hemodialysis treatments. Clin J Am Soc Nephrol 4:790-797

23. Rinat C, Becker-Cohen R, Nir A, Feinstein S, Algur N, BenShalom E, Farber B, Frishberg Y (2012) B-type natriuretic peptides are reliable markers of cardiac strain in CKD pediatric patients. Pediatr Nephrol 27:617-625

24. Wang AY, Lam CW, Yu CM, Wang M, Chan IH, Zhang Y, Lui SF, Sanderson JE (2007) N-terminal pro-brain natriuretic peptide: an independent risk predictor of cardiovascular congestion, mortality, and adverse cardiovascular outcomes in chronic peritoneal dialysis patients. J Am Soc Nephrol 18:321-330

25. Srivaths PR, Silverstein DM, Leung J, Krishnamurthy R, Goldstein SL (2010) Malnutrition-inflammation-coronary calcification in pediatric patients receiving chronic hemodialysis. hemodial Int 14:263-269

26. Rocco MV, Lockridge RS Jr, Beck GJ, Eggers PW, Gassman JJ, Greene T, Larive B, Chan CT, Chertow GM, Copland M, Hoy CD, Lindsay RM, Levin NW, Ornt DB, Pierratos A, Pipkin MF, Rajagopalan S, Stokes JB, Unruh ML, Star RA, Kliger AS, Kliger A, Eggers P, Briggs J, Hostetter T, Narva A, Star R, Augustine B, Mohr P, Beck G, Fu Z, Gassman J, Greene T, Daugirdas J, Hunsicker L, Larive B, Li M, Mackrell J, Wiggins K, Sherer S, Weiss B, Rajagopalan S, Sanz J, Dellagrottaglie S, Kariisa M, Tran T, West J, Unruh M, Keene R, Schlarb J, Chan C, Grath-Chong M, Frome R, Higgins H, Ke S, Mandaci O, Owens C, Snell C, Eknoyan G, Appel L, Cheung A, Derse A, Kramer C, Geller N, Grimm R, Henderson L, Prichard S, Roecker E, Rocco M, Miller B, Riley J, Schuessler R, Lockridge R, Pipkin M, Peterson C, Hoy C, Fensterer A, Steigerwald D, Stokes J, Somers D, Hilkin A, Lilli K, Wallace W, Franzwa B, Waterman E, Chan C, Grath-Chong M, Copland M, Levin A, Sioson L, Cabezon E, Kwan S, Roger D, Lindsay R, Suri R, Champagne J, Bullas R, Garg A, Mazzorato A, Spanner E, Rocco M, Burkart J, Moossavi S, Mauck V, Kaufman T, Pierratos A, Chan W, Regozo K, Kwok S (2011) The effects of 
frequent nocturnal home hemodialysis: the Frequent Hemodialysis Network Nocturnal Trial. Kidney Int 80:1080-1091

27. Fischbach M, Terzic J, Menouer S, Dheu C, Seuge L, Zalosczic A (2010) Daily on line haemodiafiltration promotes catch-up growth in children on chronic dialysis. Nephrol Dial Transplant 25:867-873

28. Hothi DK, Harvey E, Piva E, Keating L, Secker D, Geary DF (2006) Calcium and phosphate balance in adolescents on home nocturnal haemodialysis. Pediatr Nephrol 21:835-841
29. Pauly RP (2009) Nocturnal home hemodialysis and short daily hemodialysis compared with kidney transplantation: emerging data in a new era. Adv Chronic Kidney Dis 16:169-172

30. Canaud B, Bragg-Gresham JL, Marshall MR, Desmeules S, Gillespie BW, Depner T, Klassen P, Port FK (2006) Mortality risk for patients receiving hemodiafiltration versus hemodialysis: European results from the DOPPS. Kidney Int 69:20872093 